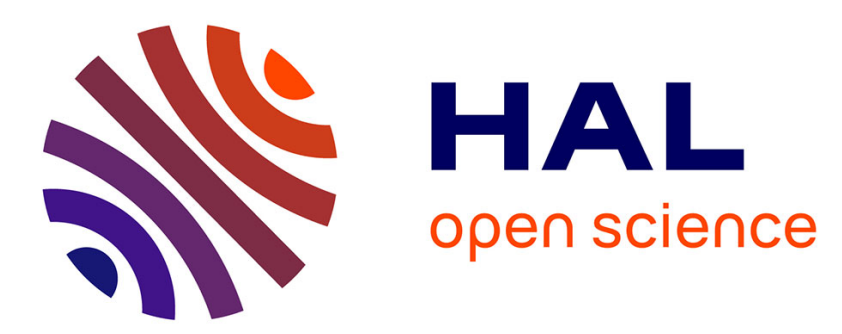

\title{
Robust Optimal Control Strategies for a Hybrid Fuel Cell Power Management System
}

David Hernández-Torres, Delphine Riu, Olivier Sename, Florence Druart

\section{To cite this version:}

David Hernández-Torres, Delphine Riu, Olivier Sename, Florence Druart. Robust Optimal Control Strategies for a Hybrid Fuel Cell Power Management System. IECON 2010 - 36th Annual Conference of the IEEE Industrial Electronics Society, Nov 2010, Phoenix, United States. hal-00545093

\section{HAL Id: hal-00545093 \\ https://hal.science/hal-00545093}

Submitted on 9 Dec 2010

HAL is a multi-disciplinary open access archive for the deposit and dissemination of scientific research documents, whether they are published or not. The documents may come from teaching and research institutions in France or abroad, or from public or private research centers.
L'archive ouverte pluridisciplinaire HAL, est destinée au dépôt et à la diffusion de documents scientifiques de niveau recherche, publiés ou non, émanant des établissements d'enseignement et de recherche français ou étrangers, des laboratoires publics ou privés. 


\title{
Robust Optimal Control Strategies for a Hybrid Fuel Cell Power Management System
}

\author{
David Hernández-Torres* ${ }^{*}$, Delphine Riu*, Olivier Sename ${ }^{\dagger}$ and Florence Druart ${ }^{\ddagger}$ \\ ${ }^{*}$ Grenoble Electrical Engineering Laboratory, 38400 Saint-Martin-D'Hères, France \\ Email: david.hernandez,delphine.riu @g2elab.grenoble-inp.fr \\ ${ }^{\dagger}$ GIPSA-Lab, Department of Control Systems, 38400 Saint-Martin-D’Hères, France \\ Email: olivier.sename@gipsa-lab.grenoble-inp.fr \\ ${ }^{\ddagger}$ LEPMI, Laboratoire d’Electrochimie et de Physicochimie des Matériaux \\ et des Interfaces, 38400 Saint-Martin-D'Hères, France \\ Email: florence.druart@lepmi.grenoble-inp.fr
}

\begin{abstract}
In this paper several optimal control strategies are proposed for the power management subsystem of a hybrid fuel cell/supercapacitor power generation system. The control strategies are based on different control configurations involving the power converters associated to the hybrid source. Given certain desired performances, Linear Matrix Inequalities methods are used to solve the controller design problem that is written as an optimization problem with inequalities constraints. The solution to the optimization problem yields a simple PID controller with $\mathcal{H}_{\infty}$ desired performance. For the several control strategies proposed, robustness is a primary issue. Time simulations and robustness analysis shows the effectiveness of the proposed strategies when compared with the classic control strategies used for this type of hybrid power generation system.

Index Terms-Robust Optimal Control, Linear Matrix Inequalities, PID control, Fuel Cells, Supercapacitors.
\end{abstract}

\section{INTRODUCTION}

As it is known, fuel cells (FC) are expected to play a very important role in the future of clean zero-emission power generation technologies. Nevertheless several technological challenges that are still blocking the FC commercial success (availability, hydrogen infrastructure, etc), have to be overcome in the following years.

The fuel cell has to be associated with a storage device (supercapacitors or batteries) in order to mitigate harmful current transients and to increase its lifespan. Classically, each component of the hybrid fuel cell control system is designed independently of each other. This approach allows simplifying the control strategy, but is not sufficient to take into account the various dynamics of the system and the coupling between thermodynamical (gas pressure) and electrical (DC current or voltage) variables. Besides, time spent for the design of the system can become critical since it is often necessary to iterate for the calculation of controller parameters. Finally, equipment suppliers should be able to design their products while knowing accurately the parameters of the whole system. However, fuel cell performances are closely linked with temperature and membrane humidification. For that purpose, robustness methods seem to be particularly adapted since they are able to deal with control issues for uncertain systems. In this paper the classic multi-loop control approach, used to add stability, see [1] and [2], is used to compare results with the proposed control strategies. In particular the control strategies proposed in [3] and [4] are used. Other practical and effective strategies are proposed in literature, see [5] for an example. A good review on different electrical power conditioning structures for FC power generation is presented in [6]. In [7] the control of the DC-DC power converter for a FC is presented, a centralized controller is studied. However no auxiliary source is used, only time result simulations are presented and no robustness evaluation is performed. Control strategies often include FC energy efficiency management, as proposed in [8]. Also see [9] for a synthetized review on energy management structures for FC hybrid systems.

In this article, the authors are interested in the optimal control of a FC system composed by a PEMFC of 500W associated with a $58 \mathrm{~F}$ supercapacitor (SC). Only the electrical performances on the DC bus are considered. The thermodynamics control is then assumed to be perfect (oxygen and hydrogen pressures are constant). To cope with implementation constraints, a control strategy involving reduced order controllers, here multivariable PI controllers with desired $\mathcal{H}_{\infty}$ performance, is considered. The simplified method of the iterative Linear Matrix Inequalities (LMI) algorithm, proposed by [10] and simplified later by [11] to compute the multivariable PI controllers, is used in this paper. Finally, $\mu$-analysis is used for the robust control analysis. In [12] the authors presented a detailed description of the methods and algorithms used in this paper. Now, in contrast, these methods are used to propose several control strategies and to compare them with other methodologies proposed in the literature. This paper is divided in four sections. In the first section the studied hybrid power generation system is presented. Then, the classic control approach is described. The proposed control strategies are detailed in the third section. Finally, results of time and frequency domains simulations are shown to validate our approach.

\section{STUDIED SYSTEM}

The studied system configuration is presented in Figure 1. The hybrid system is composed by the two sources and two 




Fig. 1. Hybrid power generation studied system.

parallel-connected boost choppers. The SC converter is not reversible, this means that the $\mathrm{SC}$ recharge from $\mathrm{FC}$ current is assured by a third converter, a flyback converter. The flyback however, is controlled independently from the boost converters. Under normal loading conditions, at approximately $475 \mathrm{~W}$, the flyback converter will drawn $0.4 \mathrm{~A}$ to keep the SC charge at a nominal voltage of $14.5 \mathrm{~V}$ in the SC. The model used for both the FC and the SC are the classic dynamic electrical equivalent model. See [13] for a review on some of the FC modeling methodologies found in literature. The state vector is chosen as:

$$
x=\left[\begin{array}{llllll}
v_{C} & i_{f c} & i_{s c} & v_{C_{c}} & v_{C_{a}} & v_{s c}
\end{array}\right]^{T}
$$

where $v_{C}$ is the DC bus voltage, $i_{f c}$ and $i_{s c}$ are the FC and SC currents, $v_{C_{c}}$ and $v_{C_{a}}$ are the double layer capacitor voltage in the cathode and anode respectively, $v_{s c}$ is the SC voltage. The system inputs $u(t)$ are given by the angles $\alpha_{f c}$ and $\alpha_{s c}$, the average values of the switching functions of the $\mathrm{FC}$ and SC power converters, $u_{f c}$ and $u_{s c}$. The load current $i_{\text {load }}$ is considered as the system output disturbance $\omega(t)$. Lowercases indicates real electrical system values.

The average modeling methodology, see [14] or [15] for an example, is used to obtain a non-linear average model of the switching system. This system is given by the following set of equations:

$$
\begin{gathered}
\frac{d V_{C_{c}}}{d t}=\frac{1}{C_{c}}\left[I_{f c}-\frac{V_{C c}}{R_{t c}}\right], \frac{d V_{C_{a}}}{d t}=\frac{1}{C_{a}}\left[I_{f c}-\frac{V_{C a}}{R_{t a}}\right] \\
\frac{d I_{f c}}{d t}=\frac{1}{L_{f c}}\left[E_{0}-V_{C_{a}}-V_{C_{c}}-R_{m} I_{f c}-\left(1-\alpha_{f c}\right) V_{C}\right] \\
\frac{d I_{s c}}{d t}=\frac{1}{L_{s c}}\left[V_{s c}-R_{s c} I_{s c}-\left(1-\alpha_{s c}\right) V_{C}\right], \frac{d V_{s c}}{d t}=\frac{1}{C_{s c}} I_{s c} \\
\frac{d V_{C}}{d t}=\frac{1}{C}\left[\left(1-\alpha_{f c}\right) I_{f c}+\left(1-\alpha_{s c}\right) I_{s c}-i_{l o a d}\right]
\end{gathered}
$$

Uppercases indicates average values. The system parameters are given in Table I and were taken from [4] for a $500 \mathrm{~W}$ PEMFC with a nominal DC bus output voltage at $24 \mathrm{~V}$. The DC bus filter capacitor is relatively large because it was designed using a conservative band-pass filter. A low-pass filter could be used instead to reduce this value.

TABLE I

FC/SC HYBRID SYSTEM PARAMETERS

\begin{tabular}{ccc} 
Parameter & Value & Units \\
\hline$E_{0}$ & 13.4 & Volts \\
$R_{m}$ & $1.28 \times 10^{-3}$ & $\Omega$ \\
$R_{t c}$ & $2.04 \times 10^{-3}$ & $\Omega$ \\
$R_{t a}$ & $4.72 \times 10^{-4}$ & $\Omega$ \\
$C_{a}=C_{c}$ & 2.12 & $\mathrm{~F}$ \\
$C_{s c}$ & 58 & $\mathrm{~F}$ \\
$R_{s c}$ & 0.019 & $\Omega$ \\
$L_{f c}=L_{s c}$ & 50 & $\mu \mathrm{H}$ \\
$C$ & 18.8 & $\mathrm{mF}$ \\
\hline
\end{tabular}

The linearized system equations are given in the state-space form:

$$
\begin{gathered}
\Delta \dot{x}=A \Delta x(t)+B_{1} \Delta \omega(t)+B_{2} \Delta u(t) \\
\Delta z(t)=C_{1} \Delta x(t)+D_{11} \Delta \omega(t)+D_{12} \Delta u(t) \\
\Delta y(t)=C_{2} \Delta x(t)+D_{21} \Delta \omega(t)
\end{gathered}
$$

where:

$$
\begin{aligned}
A & =\left[\begin{array}{cccccc}
0 & \frac{\left(1-\alpha_{f c_{e}}\right)}{C} & \frac{\left(1-\alpha_{s c_{e}}\right)}{C} & 0 & 0 & 0 \\
-\frac{\left(1-\alpha_{f c_{e}}\right)}{L_{f c}} & -\frac{R_{m}}{L_{f c}} & -\frac{R_{s c}}{L_{s c}} & \frac{1}{L_{f c}} & \frac{1}{L_{f c}} & 0 \\
-\frac{\left(1-\alpha_{s c_{e}}\right)}{L_{s c}} & 0 & 0 & 0 & 0 & \frac{1}{L_{s c}} \\
0 & \frac{1}{C_{c}} & 0 & -\frac{1}{R_{t c} C_{c}} & 0 & 0 \\
0 & \frac{1}{C_{a}} & 0 & 0 & -\frac{1}{R_{t a} C_{a}} & 0 \\
0 & 0 & -\frac{1}{C_{s c}} & 0 & 0 & 0
\end{array}\right] \\
B_{1}= & {\left[\begin{array}{llllllll}
-\frac{1}{C} & 0 & 0 & 0 & 0 & 0
\end{array}\right]^{T} } \\
B_{2}= & {\left[\begin{array}{ccccccc}
-\frac{I_{f c_{e}}}{C} & \frac{V_{C_{e}}}{L_{f c}} & 0 & 0 & 0 & 0 \\
-\frac{I_{s c_{e}}}{C} & 0 & \frac{V_{C_{e}}}{L_{s c}} & 0 & 0 & 0
\end{array}\right]^{T} }
\end{aligned}
$$

matrices $C_{1}, C_{2}, D_{11}, D_{12}$ and $D_{21}$ are specified later and depends on the chosen performance $z(t)$ and measured $y(t)$ outputs for the proposed control strategies. Subscript $e$ indicates steady-state equilibrium point. These values are given in Table II. The prefix $\Delta$ is from now on dropped for notation simplicity.

TABLE II

STEADY-STATE VALUES OF LINEAR SYSTEM

\begin{tabular}{ccccccc} 
Variable & $V_{C_{e}}$ & $I_{f c_{e}}$ & $V_{s c_{e}}$ & $V_{C a_{e}}=V_{C c_{e}}$ & $\alpha_{f c_{e}}$ & $\alpha_{s c_{e}}$ \\
\hline Value & $24 \mathrm{~V}$ & $36.7 \mathrm{~A}$ & $14.7 \mathrm{~V}$ & $0.21 \mathrm{~V}$ & 0.46 & 0.38 \\
\hline
\end{tabular}

\section{Classic Control Approach}

In this section, the load current in system 1 is modeled as $i_{\text {load }}=V_{C} / R_{L}$.

\section{A. Control Strategy proposed by Valero et al [3]}

The classic control approaches considered in [3] are based on multi-loop control. Multiple feedback control strategies are used to solve the stability problems associated with boost converter control [1]. A single current loop is used for the FC 
boost converter. The SC boost converter is chosen to control the DC bus voltage with a square output voltage loop and a second stabilizing current loop. This structure is shown in Figure 2.



Fig. 2. Hybrid system control strategy proposed in [3].

Simple PI controllers of the form $K_{p}\left(1+K_{i} / s\right)$ are used for $K_{F C}, K_{S C_{1}}$ and $K_{S C_{2}}$. The controller parameters are computed using pole compensation approaching a second order closed loop transfer function. Usually the second-order dynamics are defined by the damping ratio $\zeta$ and the undamped natural frequency $\omega_{n}$. These parameters are obtained by means of classic time domain performance parameters as the maximum overshoot, settling time, etc. The system equations are simplified to a first order transfer functions for each source.

The transfer functions for the FC and the $\mathrm{SC}$ are given respectively by:

$$
\begin{aligned}
\frac{I_{f c}}{\alpha_{f c}} & =\frac{V_{C_{e}}}{L_{s_{f c}} s+R_{s_{f c}}} \\
\frac{I_{s c}}{\alpha_{s c}} & =\frac{V_{C_{e}}}{L_{s_{s c}} s+R_{s_{s c}}}
\end{aligned}
$$

From further analysis in of [3] and based on the structure in Figure 2, the controllers parameters for a desired settling time $t_{s}$ were chosen as:

- FC current loop $K_{F C}(s)$ :

$$
k_{p}^{F C}=\frac{1}{V_{C_{e}}}\left(\frac{6 L_{s_{f c}}}{t_{s}}-R_{s_{f c}}\right), k_{i}^{F C}=\frac{R_{s_{f c}}}{L_{s_{f c}}}
$$

- SC voltage loop $K_{S C_{1}}(s)$ :

$$
k_{p}^{S C_{1}}=\frac{1}{V_{s c_{e}}}\left(C \zeta_{v} \omega_{n_{v}}-\frac{1}{R_{L}}\right), k_{i}^{S C_{1}}=\frac{\omega_{n_{v}}^{2} C}{2 k_{p} V_{s c_{e}}}
$$

- SC current loop $K_{S C_{2}}(s)$ :

$$
k_{p}^{S C_{2}}=\frac{\omega_{n_{i}} L_{s_{s c}}-R_{s_{s c}}}{V_{C_{e}}}
$$

Using the parameters in Table I and choosing $t_{s}=5 \mathrm{msec}$, $\omega_{n_{i}}=1000 \mathrm{rad} / \mathrm{s}, \omega_{n_{v}}=100 \mathrm{rad} / \mathrm{s}$ and $\zeta_{v}=1$, the simulation result, obtained with the non-linear average model for a $5 \%$ voltage reference step at $t=1 \mathrm{sec}$ and a $50 \%$ disturbance step at $t=2 \mathrm{sec}$, is shown in Figure 3.

For this test case, the current references $I_{f c}^{*}$ and $I_{s c}^{*}$ in Figure 2 are computed using an adapted filtered signal of the

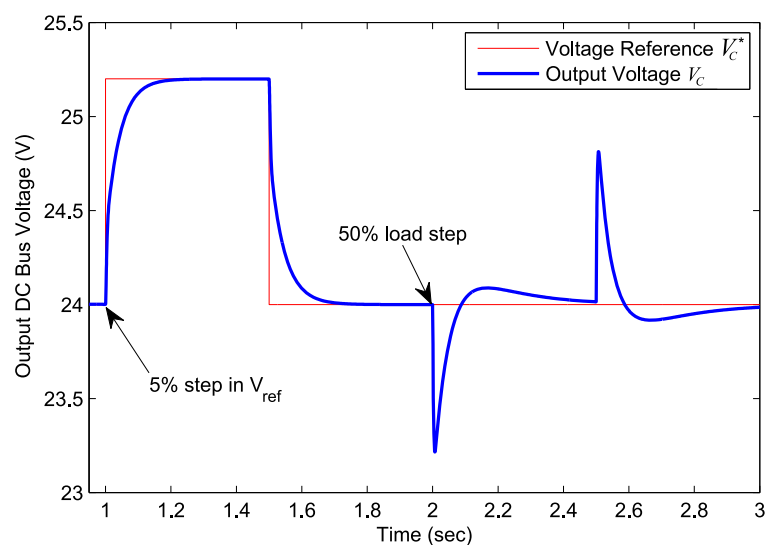

Fig. 3. Output voltage time response, method [3].

load current demand. The cut-off frequency of the filter is fixed at $1 \mathrm{~Hz}$. Then for computing the FC current reference $I_{f c}^{*}$, the low-frequency component of the load current is used with the following known steady-state relationship:

$$
I_{f c}^{*}=\frac{I_{l o a d}^{L F}}{1-\alpha_{f c}}
$$

With this strategy the SC supplies the instantaneous transient current while the FC current has a smooth response to the disturbance, keeping a healthy FC operation. Other constraints could be added to the FC dynamic, as the classic slope constraint with respect to the current density to avoid the so-called starvation problem [5].

\section{B. Control Strategy proposed by Sailler et al [4]}

A slightly modified version of the control strategy proposed in [4] is presented in Figure 4.

In this case, the FC control ensures the $\mathrm{DC}$ bus voltage control. Following the same procedure described before, the controller parameters are chosen as:

- FC voltage loop:

$$
k_{p}^{F C}=\frac{1}{V_{f c_{e}}}\left(C \zeta_{v} \omega_{n_{v}}-\frac{1}{R_{L}}\right), k_{i}^{F C}=\frac{\omega_{n_{v}}^{2} C}{2 k_{p} V_{f c_{e}}}
$$

For $\omega_{n_{v}}=480 \mathrm{rad} / \mathrm{s}$ and $\zeta_{v}=0.707$ the result shown in Figure 5 is obtained with the non-linear average model for a

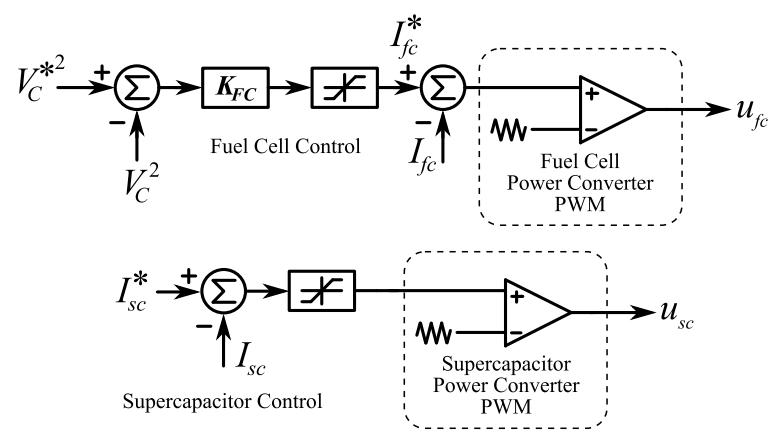

Fig. 4. Hybrid system control strategy proposed in [4]. 
$5 \%$ voltage reference step at $t=1 \mathrm{sec}$ and a $50 \%$ disturbance step at $t=2 \mathrm{sec}$.

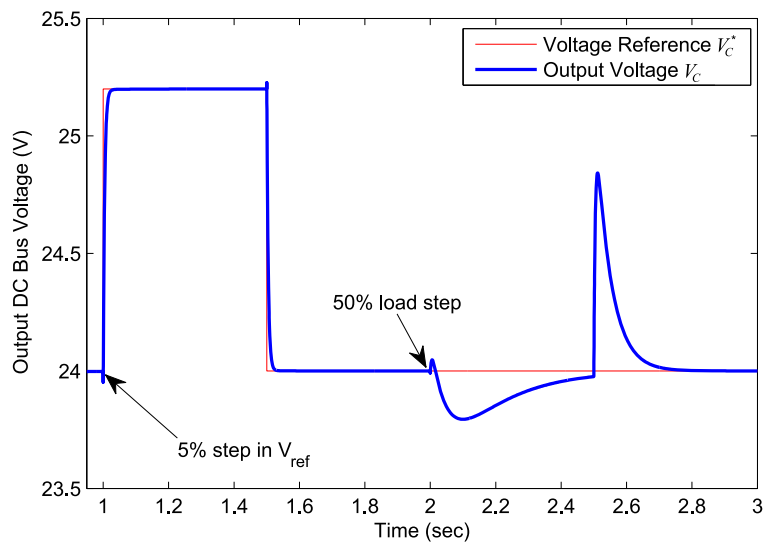

Fig. 5. Output voltage time response, method [4].

\section{Proposed Control Strategies}

FC are very sensitive to fast current transients that could shortens its lifespan. It is assumed that a better performance on disturbance rejection could be achieved with a new control design, as opposed to those shown in the previous section. We are also interested in guaranteeing robustness to system parametric uncertainties.

The proposed control strategies are then based on a multivariable PI controller with $\mathcal{H}_{\infty}$ performance. We use a simplified version of the algorithm proposed by [11], where an iterative algorithm is used to solve the LMI problem that results from imposing some constraints to the system (2). The output-feedback through LMI optimization tools is presented in [16]. In this algorithm the PI controller is transformed into a Static Output Feedback controller (SOF) and then the controller is found solving the $\mathcal{H}_{\infty}$ control problem. The problem formulation of a PID controller into the SOF form is proposed in [10]. For a multivariable PI controller, the control law is given by:

$$
u(t)=F_{1} y(t)+F_{2} \int_{0}^{t} y(\theta) d \theta
$$

With equation (6) and system (2), the $\mathcal{H}_{\infty}$ control problem formulation yields a Bilinear Matrix Inequality (BMI) problem, which is solved using the iterative LMI (iLMI) algorithm proposed by [11]. The BMI is given by:

$$
\left[\begin{array}{ccc}
P A_{c l}+A_{c l}^{T} P & P B_{c l} & C_{c l}^{T} \\
B_{c l}^{T} & -\gamma I & D_{c l}^{T} \\
C_{c l} & D_{c l} & -\gamma I
\end{array}\right] \prec 0
$$

with: $A_{c l}=A+B_{2} F C_{2}, B_{c l}=B_{1}+B_{2} F D_{21}, C_{c l}=C_{1}+$ $D_{12} F C_{2}, D_{c l}=D_{11}+D_{12} F D_{21}$ and $F=\left[\begin{array}{ll}F_{1} & F_{2}\end{array}\right]$.

This control strategy is presented in more detail for this type of system in [12], with a description of the simplified iLMI algorithm used.



Fig. 6. First proposed control structure.

\section{A. First Proposed Structure}

In the $\mathcal{H}_{\infty}$ methodology, the desired performances are expressed in the form of weighting functions on the chosen output performances $z(t)$. For this first strategy the DC bus output voltage and the FC current errors, as well as the control inputs, are chosen as performance outputs. The measured outputs are the DC bus output voltage and the FC current. This structure is detailed in Figure 6. The weighting functions are in the form [17]:

$$
W_{\text {perf }}=\frac{s / M+\omega_{B}}{s+\omega_{B} A}, W_{u}=\frac{s+\omega_{B C} / M_{u}}{A_{u} s+\omega_{B C}}
$$

Weighting functions are chosen to keep a good trade-off between a relative fast time response and the system robustness. Time simulation results using the non-linear average model is shown in Figure 7. The time simulation is obtained for a $5 \%$ step in the voltage reference at $t=3 \mathrm{sec}$ and for a $50 \%$ disturbance at $t=6 \mathrm{sec}$. The $\mathrm{FC}$ reference current is computed with the same filter used in the previous section.

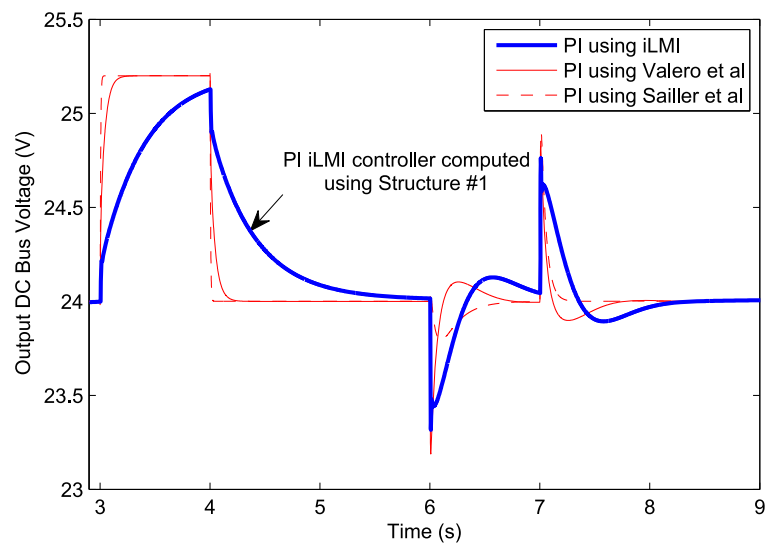

Fig. 7. Output voltage time response with the first proposed control structure. 
From the time simulation results shown in Figure 7 it is clear that the disturbance rejection performance obtained with the PI iLMI controller is similar to that obtained with the classic control strategies. However, with the general formulation of the proposed methodology, the disturbance and the closed -loop performances could improved, with a loss in the robustness as a drawback. Despite this, the proposed strategy is interesting considering the robust performance and the fact that the FC current is controlled directly, this could be useful for the practical implementation of the controller. A second structure is now proposed.

\section{B. Second Proposed Structure}

In this strategy the output DC voltage and the SC current are chosen as the measured output. The pulsation of the output voltage performance weighting function is chosen at $5 \mathrm{rad} / \mathrm{s}$. That of the SC current is fixed smaller by two decades. The time simulation is obtained for a $5 \%$ step in the voltage reference at $t=1 \mathrm{sec}$ and for a $50 \%$ disturbance at $t=2 \mathrm{sec}$. Results are shown in Figures 8 and 9. The multivariable controller obtained with this structure is given by:

$$
P I_{i L M I}=\left[\begin{array}{cc}
0.0017+0.3937 / s & 0.0031 / s \\
4.5432+103.0451 / s & 0.5964+22.7415 / s
\end{array}\right]
$$

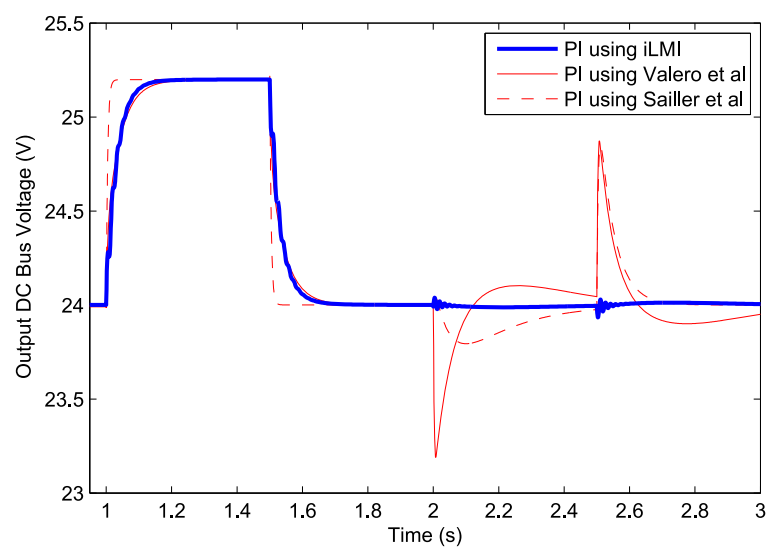

Fig. 8. Output voltage time response with the second proposed control structure.

Considering the results obtained, with this second strategy the disturbance rejection performance is considerably improved. A drawback of this strategy is that the FC current is not controlled directly. A third strategy measuring all three variables $V_{C}, I_{f c}$ and $I_{s c}$ was also considered with no better performance obtained. Optimization convergence time to compute controller parameters also increases with a higher number of measured variables.

\section{Robustness Analysis}

In this section the robustness analysis of the retained proposed strategy is presented. Results are compared to those obtained with the classic control structures. A full order $\mathcal{H}_{\infty}$ was also computed as a reference. However, other robust

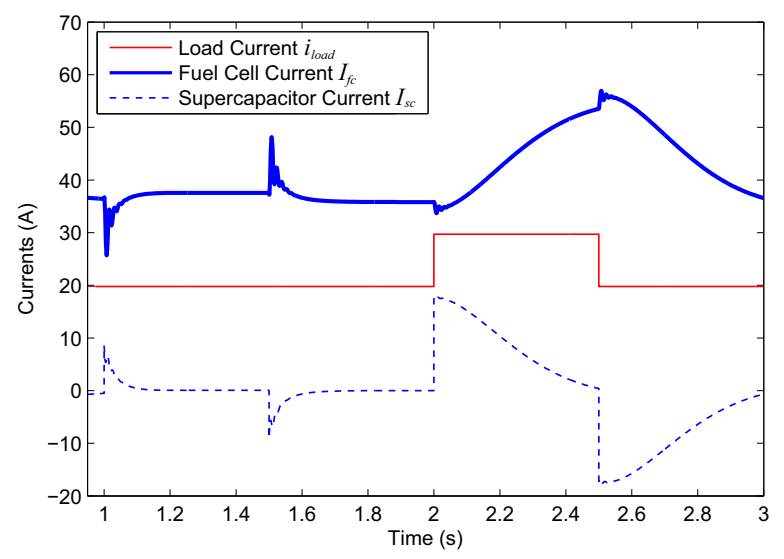

Fig. 9. System currents time response using the PI iLMI control.

reduced order controllers could be tested, for example using the algorithm developed by [18] with good results.

The robustness analysis presented in this paper is based in the $\mu$-analysis theory. See [17] for a detailed description of this theory. Uncertainties are modeled using the unstructured input-multiplicative form, and they are representative of variations in the parameters describing the system in Figure 1 (inductances, capacitors, resistances, etc). For the $\mu$-analysis, the system is first re-arranged using the perturbed general control configuration [17].

In this paper the Robust Stability (RS) test is considered. If, given the system uncertainties, the value of $\mu$ is lower than 1, then it can be concluded that the system achieves stability. A stability margin can then be found for the uncertain parameters. RS is computed using the MATLAB function mussv. Results of the RS test are presented in Figure 10. The RS plot is obtained for a given example of $20 \%$ uncertainties in inductances and capacitors, and $40 \%$ uncertainties in resistances. This is summarized in Table III. From Figure 10 it is clear that a better robust stability is obtained with the proposed control strategy with a multivariable PI controller. The maximum value of $\mu$ is around 1 , so it can be concluded that the controller guaranties stability for this level of uncertainty. This is not the case for the others controllers compared, where $\mu>1$ and stability is not guaranteed.

TABLE III

PARAMETRIC UNCERTAINTIES CONSIDERED

\begin{tabular}{cc} 
Parameter & Uncertainty (\%) \\
\hline$R_{m}, R_{t c}, R_{t a}, R_{s c}$ & \pm 40 \\
$C_{a}=C_{c}, C_{s c}, C, L_{f c}=L_{s c}$ & \pm 20 \\
\hline
\end{tabular}

With the multivariable PI controller the best performance is obtained for the time response and robustness trade-off. The robustness trade-off can be easily manipulated using the generalized control strategy used in this paper, by means of the weighting functions. In Table IV the maximum values of $\mu$ for RS are resumed. The PI iLMI controller withstands almost the $100 \%$ of the uncertainty considered. The stability margin (\% of uncertainty) comparison is presented in Table V. 


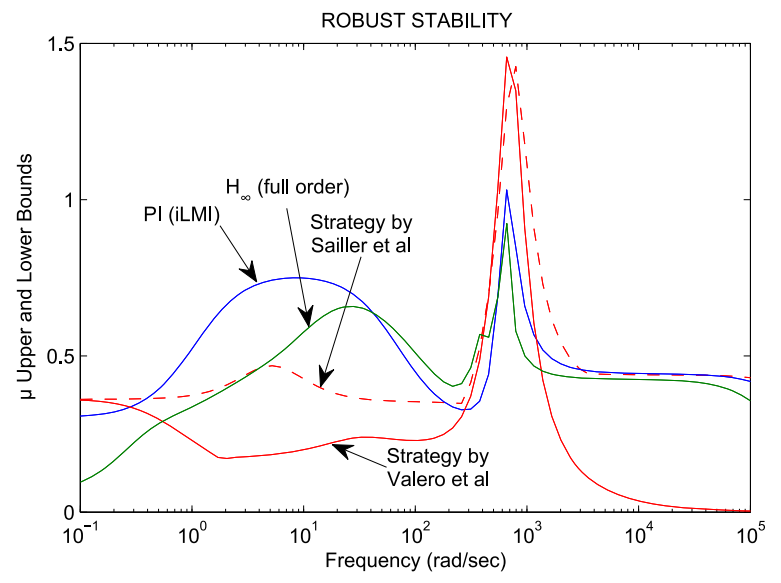

Fig. 10. Robust stability structured singular values plot.

TABLE IV

MAXIMUM $\mu$ VALUES FOR RS

\begin{tabular}{cc} 
Method & $\mu_{\max }(R S)$ \\
\hline Valero et al [3] & 1.46 \\
Sailler et al [4] & 1.43 \\
PI iLMI & 1.03 \\
Full order $\mathcal{H}_{\infty}$ & 0.90 \\
\hline
\end{tabular}

TABLE V

STABILITY MARGINS FOR RS

\begin{tabular}{ccc} 
Method & Parameter & Uncertainty (\%) \\
\hline Valero et al [3] & Resistances & \pm 27 \\
& Capacitors/Inductances & \pm 14 \\
Sailler et al [4] & Resistances & \pm 28 \\
& Capacitors/Inductances & \pm 14 \\
PI iLMI & Resistances & \pm 39 \\
& Capacitors/Inductances & \pm 19 \\
Full order $\mathcal{H}_{\infty}$ & Resistances & \pm 44 \\
& Capacitors/Inductances & \pm 22 \\
\hline
\end{tabular}

A deeper analysis on the importance of robustness can be done. The results on the robustness of the whole control strategy could be exploited in different ways. In the design process of an equipment, in this case the hybrid power generator, it could be important to minimize certain physical parameters, as the mass or the volume in the case of an on-board or a transport application. In that case robustness can be linked to the system mass minimization, this was presented for an on-board HVDC system in [19]. A better robustness could also imply a better performance when interconnecting several system equipments (several hybrid sources for example) that were designed by different manufacturers. In that case, uncertainty is considered in terms of the unknown system structure. Another approach could include a controller that exhibits robustness to a system load variation, an external disturbance. The system robustness could then lead to further design objectives.

\section{CONCLUSION}

A complete multivariable control analysis is presented in this paper. Different proposed control strategies were compared to classic control structures. Time simulation results and robustness analysis shows the effectiveness of the proposed methodologies. Moreover, the first proposed control strategy could be retained as good option for a practical implementation of the robust controller. The practical implementation of the proposed control can be easily achieved since it is based on simple PI controllers. It was relevant for the authors to show the importance of the contribution of the generalized control strategy used in this paper (using the powerful LMI tools) to improve the controller robustness.

\section{REFERENCES}

[1] R. D. Middlebrook, "Topics in multiple-loop regulators and currentmode programming," Power Electronics, IEEE Trans. on, vol. PE-2, no. 2, pp. 109-124, April 1987.

[2] J. Alvarez-Ramirez, I. Cervantes, G. Espinosa-Perez, P. Maya, and A. Morales, "A stable design of PI control for DC-DC converters with an RHS zero," Circuits and Systems I: Fundamental Theory and Applications, IEEE Trans. on, vol. 48, no. 1, pp. 103-106, Jan. 2001.

[3] I. Valero, "Interfaçage et contrôle commande de piles à combustible pour applications stationnaires et transport (in french)," Ph.D. dissertation, Grenoble Electrical Engineering Laboratory, 2004.

[4] S. Sailler, F. Druart, D. Riu, and P. Ozil, "Simulation of a PEMFC-super capacitor hybrid system," in 18th European Symposium on Computer Aided Process Engineering ESCAPE 18, 2008.

[5] P. Thounthong, S. Raël, and B. Davat, "Energy management of fuel cell/battery/supercapacitor hybrid power source for vehicle applications," Journal of Power Sources, vol. 193, no. 1, pp. 376 - 385, 2009.

[6] X. Yu, M. Starke, L. Tolbert, and B. Ozpineci, "Fuel cell power conditioning for electric power applications: a summary," IET Electric Power Applications, vol. 1, no. 5, pp. 643-656, 2007.

[7] K.-W. Suh and A. G. Stefanopoulou, "Coordination of converter and fuel cell controllers," International Journal of Energy Research, vol. 29, no. 12, pp. 1167-1189, 2005.

[8] Y. Song, S. Han, X. Li, S. Park, H. Jeong, and B. Jung, "A power control scheme to improve the performance of a fuel cell hybrid power source for residential application," in Power Electronics Specialists Conference, 2007. PESC 2007. IEEE, June 2007, pp. 1261-1266.

[9] I. Valero, S. Bacha, and E. Rulliere, "Comparison of energy management controls for fuel cell applications," Journal of Power Sources, vol. 156, no. 1 , pp. $50-56,2006$.

[10] F. Zheng, Q. G. Wang, and T. H. Lee, "On the design of multivariable PID controllers via LMI approach," Automatica, vol. 38, pp. 517-526, March 2002.

[11] Y. He and Q.-G. Wang, "An improved ILMI method for static output feedback control with application to multivariable PID control," IEEE Trans. on Automatic Control, vol. 51, pp. 1678-1683, Oct. 2006.

[12] D. Hernandez-Torres, D. Riu, O. Sename, and F. Druart, "On the robust control of DC-DC converters: Application to a hybrid power generation system," in 4th IFAC Symposium on System, Structure and Control (Submitted for publication), Sep. 2010.

[13] D. Hissel, C. Turpin, S. Astier, L. Boulon, and et al., "A review on existing modeling methodologies for PEM fuel cell systems," in Fundamentals and Developments of Fuel Cells Conference 2008 FDFC2008, Dec. 2008.

[14] R. D. Middlebrook and S. Cuk, "A general unified approach to modelling switching-converter power stages," International Journal of Electronics, vol. 42, pp. 521-550, 1977.

[15] S. Bacha, M. Brunello, and A. Hassan, "A general large signal model for DC-DC symmetric switching converters," Electric Machines and Power Systems, vol. 22, pp. 493-510, July 1994.

[16] C. Scherer, P. Gahinet, and M. Chilali, "Multiobjective output-feedback control via LMI optimization," Automatic Control, IEEE Trans. on, vol. 42, no. 7, pp. 896-911, Jul. 1997.

[17] S. Skogestad and I. Postlethwaite, Multivariable Feedback Control: Analysis and Design. New York, USA: Jhon Wiley \& Sons, 1996.

[18] S. Gumussoy, D. Henrion, M. Millstone, and M. Overton, "Multiobjective robust control with HIFOO 2.0," in Proc. of the IFAC Symposium on Robust Control Design, 2009.

[19] D. Hernandez-Torres, M. Sautreuil, N. Retière, D. Riu, and O. Sename, "A new methodology for aircraft hvdc power systems design," in Industrial Technology, 2009. ICIT 2009. IEEE Int. Conf. on, Churchill, Australia, Feb. 2009, pp. 166-171. 